\title{
A TERRITORIALIZAÇÃO DO PROGRAMA DE AQUISIÇÃO DE ALIMENTOS (PAA) EM SANTA CATARINA (2009-2018)
}

\section{THE TERRITORIALIZATION OF THE FOOD AQUISITION PROGRAM (PAA) IN SANTA CATARINA (2009-2018)}

\section{LA TERRITORIALIZCIÓN DEL PROGRAMA DE AQUISICION DE ALIMENTOS (PAA) EM SANTA CATARINA (2009-2018)}

\author{
Cleber José Bosetti ${ }^{1}$ \\ https://orcid.org/0000-0003-3117-8998
}

Submissão: 27/05/2020 / Aceito: 01/10/2020 / Publicado: 30/09/2021.

\begin{abstract}
Resumo
Este trabalho faz uma análise da territorialização do Programa de Aquisição de Alimentos (PAA) em diferentes regiões do Estado de Santa Catarina no período compreendido entre 2009-2018. O PAA é entendido aqui como parte das políticas públicas de fortalecimento da agricultura familiar, bem como um instrumento das políticas de melhoria da segurança alimentar e nutricional do país. Os objetivos do trabalho são apresentar a distribuição regional do PAA no referido território, compreender os aspectos que caracterizam essa distribuição e analisar o papel das associações/cooperativas como entidades viabilizadoras dos mercados institucionais e do desenvolvimento rural. A metodologia utilizada foi quantitativa, através de análises estatísticas acerca dos dados do PAA. Os resultados sinalizam que, apesar de algumas limitações operacionais, o PAA possui um potencial para geração de desenvolvimento no âmbito territorial, especialmente quando o próprio território possui ancoradouros sociopolíticos convergentes com os princípios e diretrizes dessa política pública.
\end{abstract}

Palavras-chave: PAA, agricultura familiar, associações/cooperativas, desenvolvimento rural.

\begin{abstract}
This work analyzes the territorialization of the Food Acquisition Program (PAA) in different regions of the State of Santa Catarina in the period between 2009-2018. The PAA is understood here as part of public policies to strengthen family agriculture, as well as an instrument of policies to improve food and nutrition security in the country. The objectives of the work are to present the regional distribution of the PAA in that territory, understand the aspects that characterize this distribution and analyze the role of associations/cooperatives as enabling entities of institutional markets and rural development. The methodology used was quantitative through statistical and content analysis about PAA data. The results indicate that, despite some operational limitations, the PAA has a potential for generating development at the territorial level, especially when the
\end{abstract}

\footnotetext{
${ }^{1}$ Doutor em Sociologia Política pela Universidade Federal de Santa Catarina-UFSC; professor do Centro de Ciências Rurais-CCR/UFSC.
} 
territory itself has socio-political anchorages converging with the principles and the guidelines this public policy.

Key-Words: PAA, family farming, associations/cooperatives, rural development.

\section{Resumen}

Este trabajo analiza la territorialización del Programa de Adquisición de Alimentos (PAA) en diferentes regiones del Estado de Santa Catarina en el período 2009-2018. El PAA se entiende aquí como parte de las políticas públicas de fortalecimiento de la agricultura familiar, así como un instrumento de políticas para mejorar la seguridad alimentaria y nutricional en el país. Los objetivos del trabajo son presentar la distribución regional del PAA en ese territorio, comprender los aspectos que caracterizan esta distribución y analizar el papel de las asociaciones/cooperativas como entidades que posibilitan los mercados institucionales y el desarrollo rural. La metodología utilizada fue cuantitativa, mediante análisis estadístico de los datos del PAA. Los resultados indican que, a pesar de algunas limitaciones operativas, el PAA tiene potencial para generar desarrollo en el ámbito territorial, especialmente cuando el propio territorio tiene anclajes sociopolíticos que convergen con los principios y lineamientos de esta política pública.

Palabras-clave: PAA, agricultura familiar, asociaciones / cooperativas, desarrollo rural.

\section{INTRODUÇÃO}

A concepção de soberania e segurança alimentar na atualidade compreende a quantidade, a qualidade e o acesso aos alimentos saudáveis a toda população mundial (MALUF, 2000; BELIK, 2003). Entretanto, o regime agroalimentar atual, isto é, o conjunto de formas institucionais que regula as relações de produção, troca, distribuição e consumo dos produtos agropecuários e alimentícios (MCMICHAEL, 2016; SCHNEIDER; SCHUBER; ESCHER, 2016) não consegue garantir tais condições, principalmente nos países subdesenvolvidos. A configuração desse regime agroalimentar produz dois tipos de problemas: dificuldade de sustentabilidade das formas sociais familiares de produção e dificuldade acesso aos alimentos para as populações de baixa renda.

Dante disso, uma das estratégias para melhorar o acesso e a qualidade da alimentação tem sido a construção de mercados institucionais, isto é, de uma intervenção estratégica do governo na configuração do regime agroalimentar (FLIGSTEIN; DAUTER, 2012). No Brasil, especialmente a partir da década de 2000, algumas políticas públicas foram elaboradas dentro dessa ótica. Estas políticas envolvem o incentivo à produção de alimentos pelos agricultores familiares e a sua disponibilização para segmentos sociais em situação de vulnerabilidade alimentar (BECKER; SACCO DOS ANJOS, 2015; PRZYBYZESKI, 2020). 
O Programa de Aquisição de Alimentos do Governo Federal (PAA), criado no ano de 2003, foi construído com base em dois grandes objetivos: possibilitar a melhoria da alimentação da população brasileira facilitando seu acesso aos alimentos produzidos e distribuídos diretamente pelos agricultores; e subsidiar o Programa de Fortalecimento da Agricultura Familiar (PRONAF), através de estímulos à produção e comercialização dos produtos produzidos pelos agricultores familiares. Os reflexos do programa em relação a esse segundo objetivo são o objeto principal de análise deste artigo. Assim, a partir de um estudo quantitativo acerca da distribuição regional do PAA, buscam-se compreender a importância dos arranjos associativos para a mobilização do programa, os aspectos territoriais relacionados com essa distribuição e a correlação do programa com outras políticas públicas voltadas para o desenvolvimento socioeconômico da agricultura familiar que se conectam com a soberania e segurança alimentar.

\section{MERCADOS INSTITUCIONAIS: SEGURANÇA ALIMENTAR E AGRICULTURA FAMILIAR}

O PAA foi instituído pelo Art. 19 da Lei no 10.696, de 02 de julho de 2003, no âmbito do Programa Fome Zero, e modificado de forma complementar pelo Decreto $\mathrm{n}^{\mathbf{0}} \mathbf{7 . 7 7 5}$, de 04 de Julho de 2012. Entre seus principais pontos estão: incentivar a agricultura familiar, promovendo a sua inclusão econômica e social; incentivar o consumo e a valorização dos alimentos produzidos pela agricultura familiar; promover o acesso à alimentação em quantidade, qualidade e regularidade necessárias sob a perspectiva do direito humano à alimentação adequada e saudável; promover o abastecimento alimentar, que compreende as compras governamentais de alimentos; apoiar a formação de estoques pelas cooperativas e demais organizações formais da agricultura familiar; e fortalecer circuitos locais e regionais e redes de comercialização (BRASIL, 2003; 2012).

A identificação das mudanças nos padrões alimentares da população brasileira e sua vinculação com o aumento de doenças (TRICHES; SCHNEIDER, 2010), bem como os problemas de acesso aos alimentos por parte da população, fizeram do PAA uma extensão do Programa Fome Zero implantado no ano de 2003 (HESPANHOL, 2003). Dessa forma, o PAA emergiu como uma política pública intersetorial que busca integrar outras políticas públicas, como as de segurança e soberania alimentar e o fortalecimento da agricultura familiar. 
A segurança alimentar diz respeito ao direito de acesso aos alimentos de qualidade para a população $(B E L I K, 2003)$ e a soberania alimentar refere-se à importância da autonomia alimentar dos países, incluindo à geração de emprego e a menor dependência das importações e flutuações de preços do mercado internacional (MALUF, 2000). Ao conectar-se com o PRONAF, a partir da perspectiva da construção social de mercados para os agricultores familiares (GRISA; SCHMITT; MATTEI; MALUF; LEITE, 2010), o PAA constituiu-se como uma política pública vinculada à soberania e segurança alimentar, pois fortalece uma maior autonomia em termos de produção e acesso aos alimentos.

No que se refere às políticas de fortalecimento da agricultura familiar, o PAA pode ser considerado como parte de uma terceira geração de políticas públicas. Enquanto a primeira geração possuía características muito difusas, sem uma distinção específica para a agricultura familiar; a segunda, da qual faz parte o PRONAF, caracterizou-se pelo foco na produção agrícola dos agricultores familiares e na redução da pobreza rural; por sua vez, a terceira geração pautou-se na construção social dos mercados, com ênfase na comercialização dos produtos da agricultura familiar (SCHNEIDER; GRISA, 2014). Neste sentido, o PAA pode ser compreendido como um programa complementar aos objetivos do PRONAF, ou seja, busca o desenvolvimento socioeconômico da agricultura familiar.

A orientação do PAA enquanto política pública de incentivo à comercialização da agricultura familiar, fez com que esse programa se constituísse enquanto mercado institucional dos circuitos curtos de comercialização (DARLOT; LAMINE; BRANDEMBURG, 2013; ROVER; RIEPE, 2015), isto é, um mercado em que o Estado realiza a mediação entre os produtores e consumidores. Dessa forma, o programa busca integrar e aproximar o agricultor familiar e o consumidor urbano, ambos distanciados e por vezes desconectados em função dos imperativos do atual regime agroalimentar corporativo (MCMICHAEL, 2016).

Enquanto política pública, o PAA teve como avaliações positivas a alteração na matriz produtiva e de consumo dos beneficiários, a articulação entre produção e consumo; a criação de novos mercados e o resgate e fortalecimento de práticas e produtos tradicionais e regionais; por outro lado, como depende da governança, do capital social e da mobilização dos atores locais, a fragilidade das organizações, a instabilidade política das administrações públicas municipais, são alguns dos seus pontos fracos (TRICHES; GRISA, 2015). Isso ocorre porque processo de territorialização da ação pública, isto é, a implementação 
articulada de um conjunto de políticas públicas num território por meio da concertação entre gestores públicos e atores da sociedade civil para a sua gestão social (TECCHIO; CAZELLA, 2021), demanda uma série de orquestrações e habilidades técnicas e sociopolíticas para efetivar seus objetivos.

Em termos operacionais, o PAA compreende duas modalidades: a) os alimentos são adquiridos pelo governo diretamente dos agricultores familiares para a doação às entidades das redes socioassistenciais (restaurantes populares, bancos de alimentos, cozinhas comunitárias, entre outros); b) alimentos são adquiridos pelas próprias organizações da agricultura familiar para formação de estoques próprios (TRICHES; GRISA, 2015; PRZYBYZESKI, 2020). O PAA foi executado até o ano de 2016 pelo Ministério do Desenvolvimento Social (MDS) e pelo Ministério do Desenvolvimento Agrário (MDA). Posteriormente, passou para o Ministério da Cidadania, em parceria com a Companhia Nacional de Abastecimento (CONAB), que recebem as demandas solicitadas por Estados e Municípios responsáveis pela mediação dos contratos individuais ou coletivos entre os agricultores e o governo federal. Nisso, a mobilização dos agentes públicos da administração pública federal e local, bem como dos agricultores familiares e suas organizações, são cruciais para o funcionamento do programa.

Por isso, um dos pontos institucionalizados pelo PAA é a organização dos agricultores em associações e cooperativas. As associações são entidades civis constituídas com o intuito de estimular a cooperação dos agentes sociais com objetivos diversos; as cooperativas são entidades que também buscam fortalecer a cooperação dos agentes sociais para a realização de objetivos comuns, tendo nas atividades com fins comerciais um dos objetivos principais (ABRANTES, 2004). No caso da agricultura familiar, os arranjos associativos e cooperativos são mecanismos para potencializar os ótimos diferenciais, isto é, para impulsionar as capacidades de se obter bons rendimentos nas unidades socioprodutivas (CHAYANOV, 2017). Na operacionalização do PAA, as associações/cooperativas funcionam como mediadoras e facilitadoras do processo que, quando providas de capital social e capacidade empreendedora, podem auxiliar nos mecanismos de organização da produção e comercialização dos agricultores.

A fim de compreender os impactos do PAA, especialmente no que diz respeito ao seu objetivo de fortalecer a agricultura familiar, torna-se importante observar a relação entre esta política pública e as dinâmicas territoriais que dão substrato a sua operacionalização. 
Neste sentido, a abordagem territorial é uma das possibilidades teóricas que auxiliam na compreensão da aplicação e desempenho das políticas públicas. Para isso, são necessárias algumas considerações acerca dos conceitos de território, territorialidade e territorialização.

O território consiste nos componentes materiais ordenados no espaço, tanto pela natureza quanto pelas delimitações estabelecidas pela ação humana com objetivos diversos (GOTTMANN, 2012). Já o ambiente constitui a matéria prima sobre a qual o ser humano trabalha para produzir, socialmente, o território (RAFESTIN, 2009). Assim, o território é uma construção coletiva que ocorre através das ações sociais efetivadas pela autoridade estatal, por empresários, por organizações políticas e por agentes sociais em geral ao longo do processo histórico (SAQUET; BRISKIEVICZ, 2009). A territorialidade se constitui em função das relações sociais, econômicas, políticas e culturais estabelecidas por indivíduos e grupos sociais em relação a um determinado território (SAQUET; BRISKIEVICZ, 2009). Sendo o resultado dessas relações, a territorialidade ajuda a configurar as identidades, os sentimentos e as características culturais e simbólicas da experiência humana em relação ao espaço geográfico.

Políticas públicas como o PAA dependem das dinâmicas territoriais para se efetivarem e, paralelamente, são capazes de alterar tais dinâmicas na medida em que se territorializam. De certa forma, podem ser caracterizadas como políticas setoriais territorializadas, ou seja, dependem da mobilização de agentes do território para sua efetivação, ou seja, da ação governativa que compreende tanto a ação do Estado como dos agentes locais na edificação de práticas, processos e instituições (DIAS; SEIXAS, 2019; LEITE, 2020). Enquanto abordagem teórico-metodológica, a territorialização subsidia diversos estudos acerca do desenvolvimento rural, tais como o fluxo migratório de agricultores e trabalhadores rurais, o fluxo de capitais e pacotes tecnológicos e o fluxo governamental por meio das políticas públicas (LEITE, 2020). Diante disso, infere-se que a afirmação do PAA enquanto política pública depende de características e dinâmicas presentes nos territórios.

Dessa forma, o objetivo desse artigo é analisar a distribuição regional do PAA no Estado de Santa Catarina entre os anos de 2009-2018 e relacioná-la com o papel das associações/cooperativas e as dinâmicas territoriais nas quais estas últimas estão inseridas para, por fim, observar os possíveis impactos do PAA para o desenvolvimento rural no âmbito regional. Para isso foram levantados alguns questionamentos que nortearam a 
pesquisa: como se deu a distribuição regional do volume de recursos do PAA no período estudado? Há uma correlação entre o número de associações/cooperativas por região e a mobilização de recursos do programa? De que maneira as dinâmicas sociopolíticas e territoriais impactam no funcionamento do programa? É possível mensurar os impactos do programa sobre o desenvolvimento rural no âmbito local/regional? Para responder a essas perguntas foi construído o arcabouço metodológico a seguir.

\section{METODOLOGIA}

Com base nas questões norteadoras citadas anteriormente, foi feito o levantamento de informações dos contratos do PAA no Estado de Santa Catarina junto ao Ministério da Agricultura Pecuária e Abastecimento (MAPA). Os registros disponíveis no sistema são posteriores ao ano de 2009, por isso o recorte temporal da pesquisa foi de 2009-2018. No trabalho de organização dos dados, as informações foram separadas por região e foi feita a distinção entre os contratos envolvendo pessoas físicas, que representam a menor parte, e os envolvendo pessoas jurídicas, no caso associações/cooperativas, que representam a maior parte.

A definição de região foi tomada a partir da nova classificação regional estabelecida pelo Instituto Brasileiro de Geografia e Estatística (IBGE) no ano de 2017, a qual divide os Estados Federativos em regiões intermediárias e imediatas. Nessa divisão, o Estado de Santa Catarina é dividido em 07 regiões intermediárias: Florianópolis, Joinville, Blumenau, Criciúma, Lages, Caçador e Chapecó e 24 regiões imediatas, anexas as regiões intermediárias (IBGE, 2017). Além disso, foi incorporada a ideia de região como uma divisão do mundo social que se busca compreender (BOURDIEU, 2005), isto é, tomado consciência do caráter arbitrário de toda classificação e da forma que a mesma interfere no objeto de estudo.

Enquanto estratégia metodológica, a pesquisa pode ser caracterizada como quantitativa. O método de investigação utilizado foi o estatístico, método este que se fundamenta na aplicação da teoria estatística da probabilidade e constitui importante auxílio para a investigação em ciências sociais. Isso porque as técnicas estatísticas possibilitam uma melhor caracterização dos dados, bem como observar as possíveis relações entre as variáveis que ajudam a explicar determinado fenômeno (GIL, 2008). 
Em termos estatísticos, basicamente foram utilizadas as técnicas de Correlação Linear Simples e Regressão Linear para testar a capacidade explicativa das variáveis (AFONSO, 2019). A correlação e a regressão linear são duas ferramentas estatísticas que permitem analisar o comportamento conjunto de duas ou mais variáveis com o intuito de avaliar se as alterações em uma das variáveis implicam em alterações nas outras. A correlação linear é medida pelo coeficiente de correlação de Pearson que varia entre 1 e -1 , sendo que quanto mais próximo desses valores mais forte será a associação entre as variáveis (OLIVEIRA; CHATALOV, 2017; a regressão linear é medida pelo coeficiente de determinação $\mathrm{R}^{2}$ que representa a porcentagem da variação da variável dependente que é explicada pela variável independente. Este coeficiente varia de $0-1$, sendo que quanto mais próximo de 1 maior é sua capacidade explicativa (OLIVEIRA; CHATALOV, 2017; AFONSO, 2019). A análise estatística dos dados foi realizada com a utilização do programa Excel.

\section{ANÁLISE DOS DADOS E DISCUSSÃO}

A primeira questão explorada foi dimensionar a importância das associações/cooperativas nos contratos do PAA no período compreendido entre 2009-2018 em Santa Catarina. O número de agricultores participantes via associações/cooperativas foi de 35.840, enquanto que a adesão por contratos individuais foi de 3.467 (MAPA, 2019). O valor dos contratos via associações/cooperativas movimentou aproximadamente 150 milhões de reais no período referido. 
Gráfico 1: Agricultores participantes do PAA em Santa Catarina via associações/cooperativas entre os anos de 2009-2018

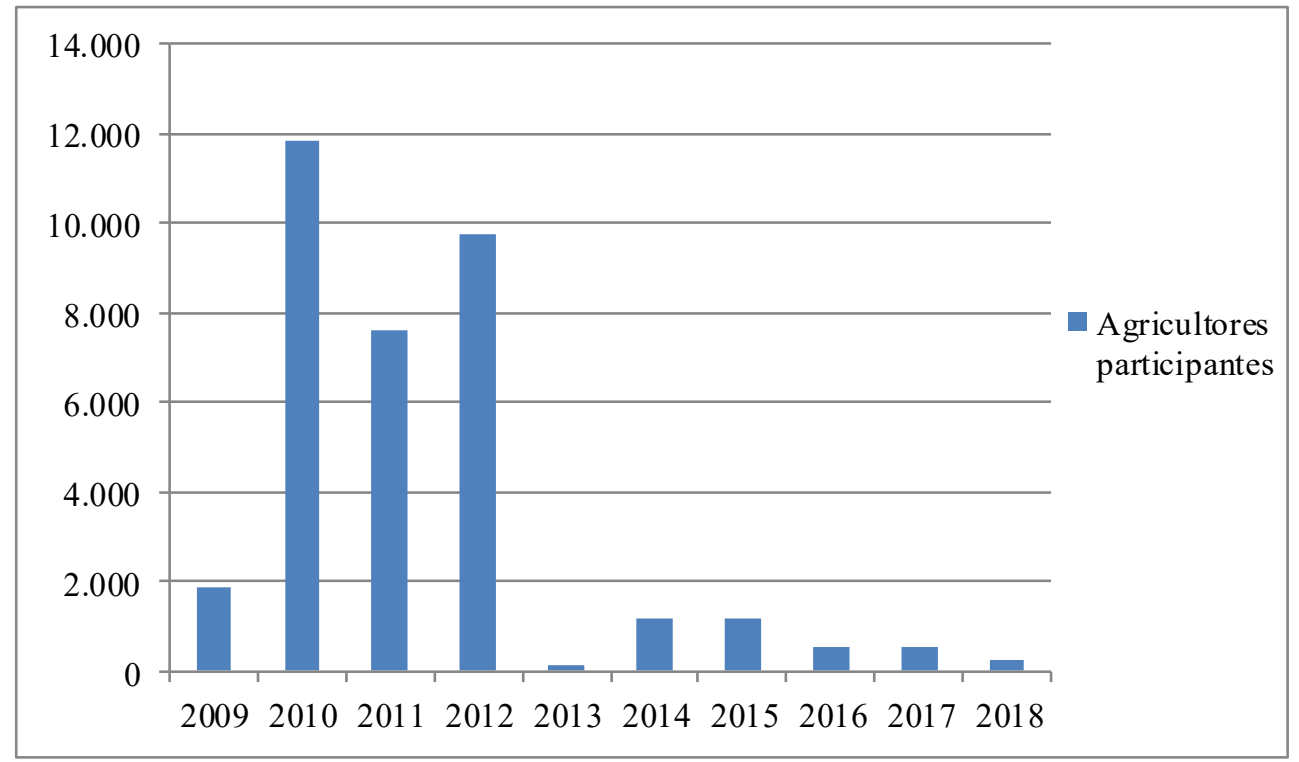

Fonte: elaborado pelo autor.

Como se vê, entre os anos de 2009-2012 houve uma maior movimentação nesse mercado e nos anos subsequentes iniciou-se um processo de enxugamento dos contratos.

Em seguida, foi estudada essa distribuição a partir da divisão regional do Estado de Santa Catarina.

Figura 1: Regiões Geográficas de Santa Catarina

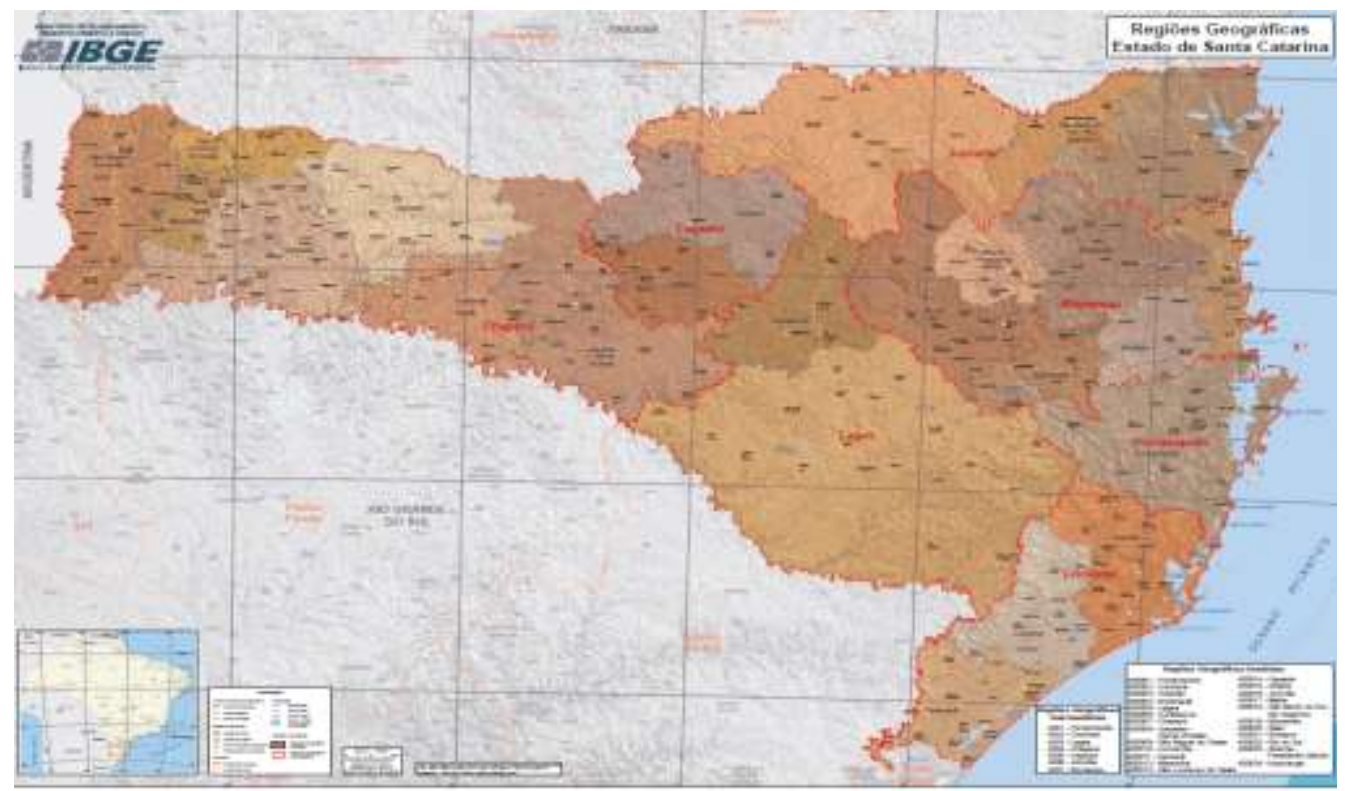

Fonte: IBGE (2017). 
Nessa classificação, a extensão territorial da região intermediária de Chapecó possui uma área mais expressiva em relação às demais. Este é um elemento que ajuda a explicar a maior aderência da mesma a políticas públicas como o PAA. A distribuição percentual da participação das cooperativas por regiões intermediárias se deu do seguinte modo:

\section{Gráfico 2:Percentual das associações/cooperativas participantes do PAA em Santa Catarina por região intermediária}

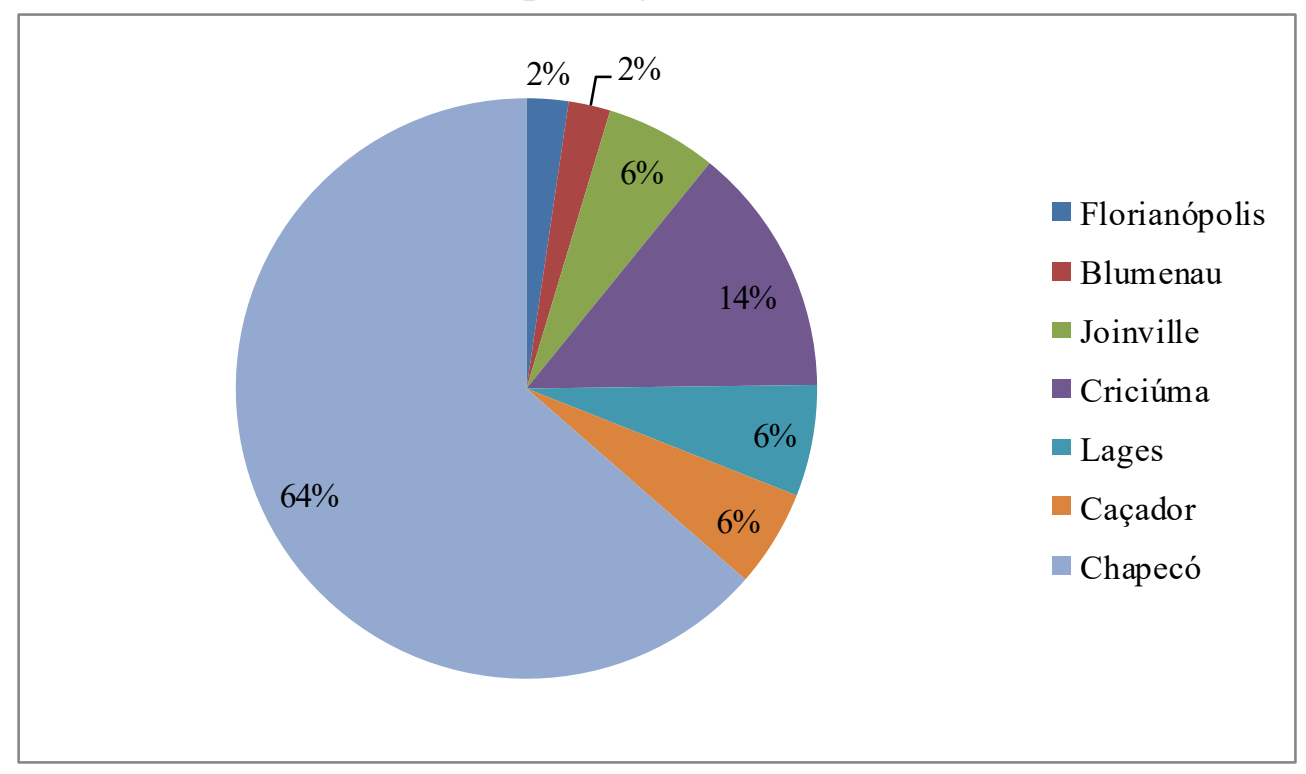

Fonte: elaborado pelo autor.

Conforme os dados apresentados no Gráfico 2, a região intermediária de Chapecó possui a maior parte das associações/cooperativas que participaram do PAA entre 20092018. Em relação ao número de agricultores participantes, os dados também apontam para um predomínio de agricultores dessa região intermediária. 
Gráfico 3: Número de agricultores participantes do PAA via associações/cooperativas por região intermediária 2009-2018

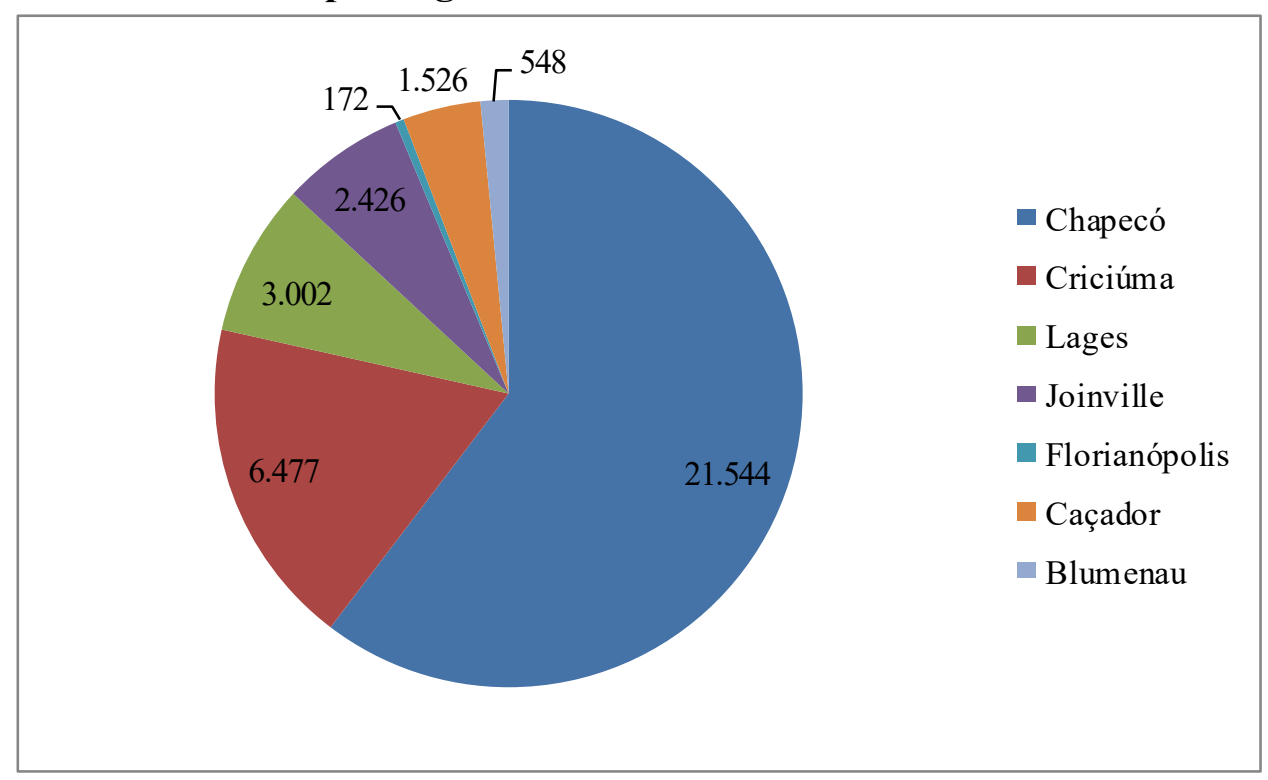

Fonte: elaborado pelo autor.

Em relação aos valores dos contratos, a distribuição do volume financeiro por região intermediária foi a seguinte.

\section{Gráfico 4: Valores dos contratos com as associações/cooperativas por regiões intermediárias no Estado de Santa Catarina no período 2009-2018}

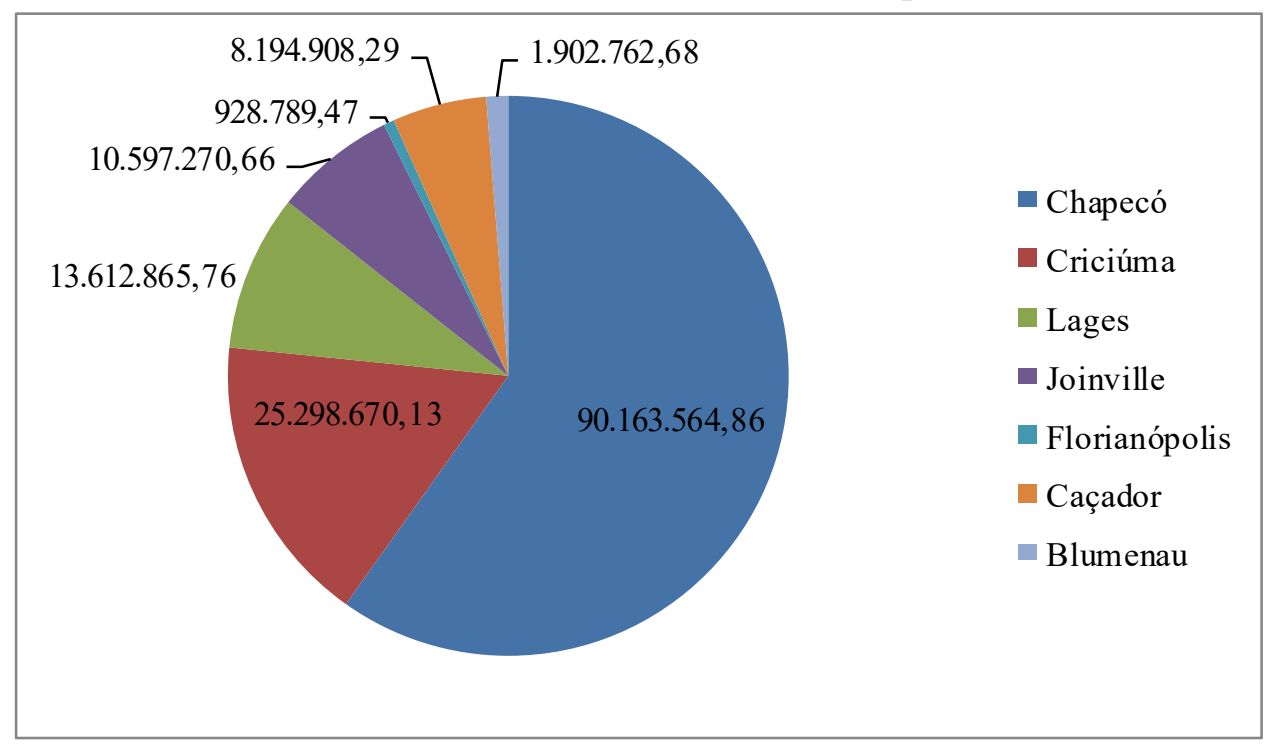

Fonte: elaborado pelo autor.

Além dos aspectos mencionados referentes à divisão regional elaborada pelo IBGE, outra explicação para essa distribuição está nas dinâmicas da história econômica de cada região. Embora, no inicio do processo de colonização, as atividades agrícolas e de produção 
de alimentos estivessem presentes e articuladas com um caráter mercantil em todas as regiões, a história econômica de cada uma delas foi adquirindo especificidades e distinções. Assim, na região sul do Estado (Criciúma) as atividades carboníferas superaram às agroindustriais; no vale do Itajaí (Blumenau) a indústria têxtil tornou-se mais preponderante; no norte (Joinville) a metal-mecânica; na Serra e Contestado (Lages, Caçador), a configuração fundiária e o extrativismo colocaram a agricultura de base familiar em segundo plano; enquanto que no oeste (Chapecó) a agroindústria ancorada em bases familiares tornou-se a principal atividade econômica (GOULARTI FILHO, 2007).

$\mathrm{O}$ aspecto da continuidade e relevância econômica das atividades agropecuárias fundamentadas na forma social familiar de produção na agricultura é, em parte, outro elemento que ajuda a explicar o porquê da maior participação da região de Chapecó em relação às demais regiões, seja em número de associações/cooperativas, de agricultores participantes e do volume de recursos alocados. Pode-se dizer, nesta perspectiva, que a territorialização da agricultura familiar nessa região, em termos socioeconômicos, é um dos aspectos decisivos para sua maior participação em políticas públicas como o PAA.

Tal territorialização envolve a construção de arranjos socioeconômicos para garantir sua permeabilidade. Com o processo de concentração vertical dos meios de produção na agricultura, a reprodução social das formas familiares é possível na medida em que determinados arranjos sociais são construídos (CHAYANOV, 2017). Neste sentido as tradições associativas/cooperativas, presentes na história social e econômica dos territórios com forte presença da agricultura familiar, também parecem influenciar, em termos de capacidade auto-organizativa dos agentes sociais, a adesão a determinadas modalidades de políticas públicas como é o caso do PAA.

$\mathrm{Na}$ região sul do Brasil as experiências associativas/cooperativas de caráter rural aconteceram em diferentes contextos históricos. Isso pode ser identificado durante o processo de colonização, nas experiências de assentamento rural ou na alocação de políticas públicas como o PAA em anos recentes (CHRISTOFFOLI, 2015). Um exemplo disso pode ser visto na política de assentamentos rurais do MST, especialmente entre as décadas de 1980-1990, quando o discurso e a política cooperativista eram enaltecidos como forma de assegurar a sustentabilidade da agricultura familiar (BOSETTI, 2017).

Políticas públicas como o PAA não somente incentivam os arranjos associativos/cooperativos, mas também se territorializam mais facilmente em espaços 
sociais que já possuem embriões desses instrumentos arraigados na trajetória social e nas práticas da agricultura familiar camponesa (SABORIN, 2009; BOSETTI, 2017). Nesta perspectiva, pode-se dizer que a configuração dos territórios rurais se combina com as políticas públicas com graus de convergência diferenciados no âmbito regional. Por isso, algumas regiões são mais aderentes que outras no que diz respeito à efetivação das políticas públicas que são operacionalizadas a partir da mobilização dos agentes sociais via organizações associativas/cooperativas. A fim de testar possíveis relações entre a participação dos agricultores no PAA via associações/cooperativas e o volume monetário mobilizado pelo programa, foram feitas análises estatísticas para verificar possíveis correlações.

A primeira análise consistiu em mensurar uma possível correlação entre o número de agricultores vinculados às associações/cooperativas com os valores dos contratos. Isso foi feito com recorte dos municípios-sede das regiões imediatas que compõe as regiões intermediárias. Essa correlação apresentou significância estatística. O Teste de Correlação Linear Simples mostrou-se significativo e a análise de Regressão Linear apresentou o Coeficiente de Determinação $R^{2}$ de $0,99 \%$, ou seja, a variável independente explica a maior parte das alterações da variável dependente.

\section{Gráfico 5: Agricultores associados/cooperados e os volume dos contratos do PAA nos municípios-sede das regiões imediatas}

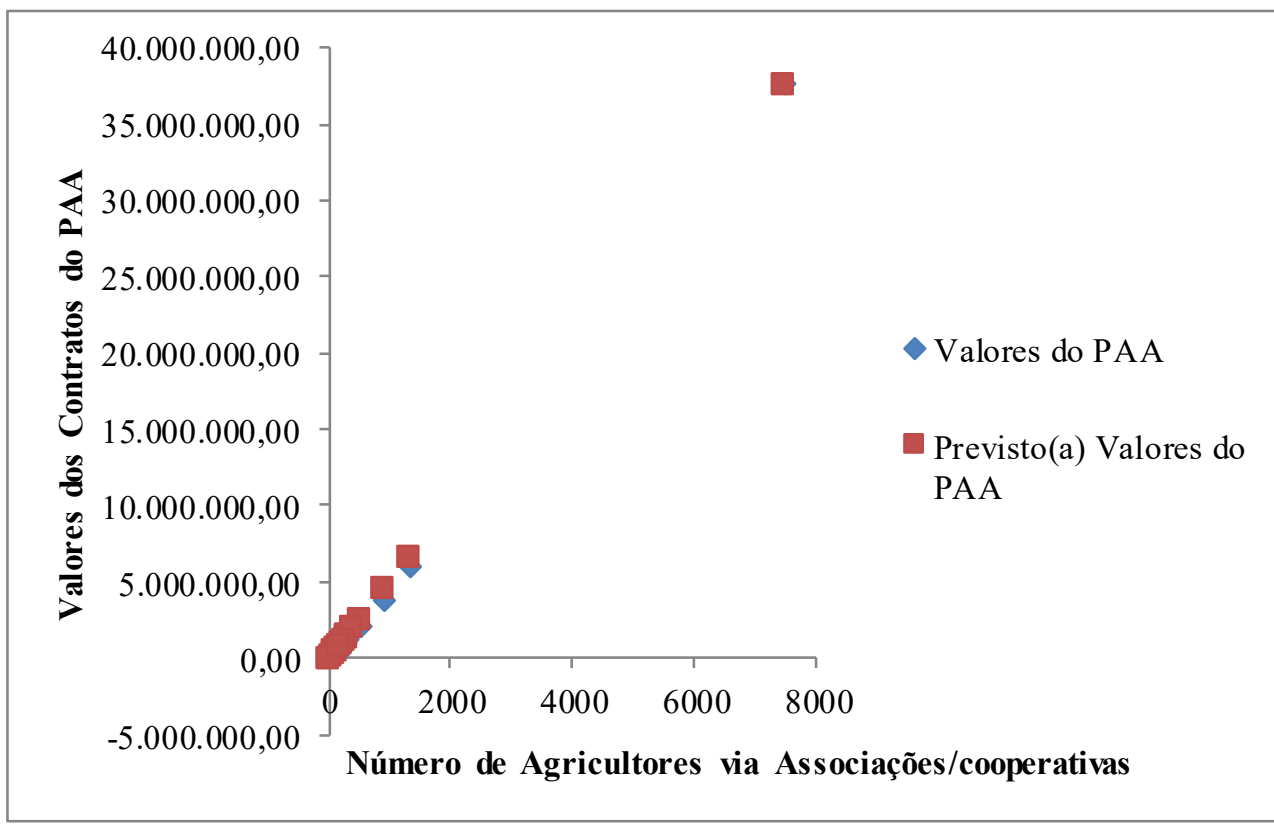

Fonte: elaborado pelo autor. 
Neste caso, o número de agricultores está condicionado ao número de associações/cooperativas existentes. Isso significa que a maior mobilização de recursos por parte do PAA no período 2009-2018 esteve condicionada a capacidade de organização dos agentes locais em entidades associativas e cooperativas. Com isso, a territorialização do programa se constitui a partir da territorialidade associativa que, por razões históricas, econômicas e sociopolíticas, está habilitada em termos de capital social e mobilização de recursos humanos para se integrar mais facilmente à política pública dos mercados institucionais. Nas regiões em que há uma convergência maior entre as dinâmicas territoriais cooperativas e a institucionalidade da política pública, esta última tende a se territorializar com maior aderência.

A segunda hipótese testada foi a existência de correlação entre a territorialização da agricultura familiar via assentamentos rurais (INCRA, 2019) e o volume de recursos contratados pelo PAA. Neste caso, o coeficiente de correlação foi de $0,88 \%$ e na Análise de Regressão Linear, o Coeficiente de Regressão $\mathrm{R}^{2}$ foi de $0,74 \%$. Os Testes F de Significação e o Valor $\mathrm{P}>5 \%$ também indicam que há correlação entre as variáveis, ou seja, a capacidade explicativa da correlação é positiva e possui relevância. A análise de Regressão Linear está expressa conforme Gráfico seguinte.

\section{Gráfico 6: Assentamentos Rurais e o volume dos contratos do PAA por região Intermediária no Estado de Santa Catarina}

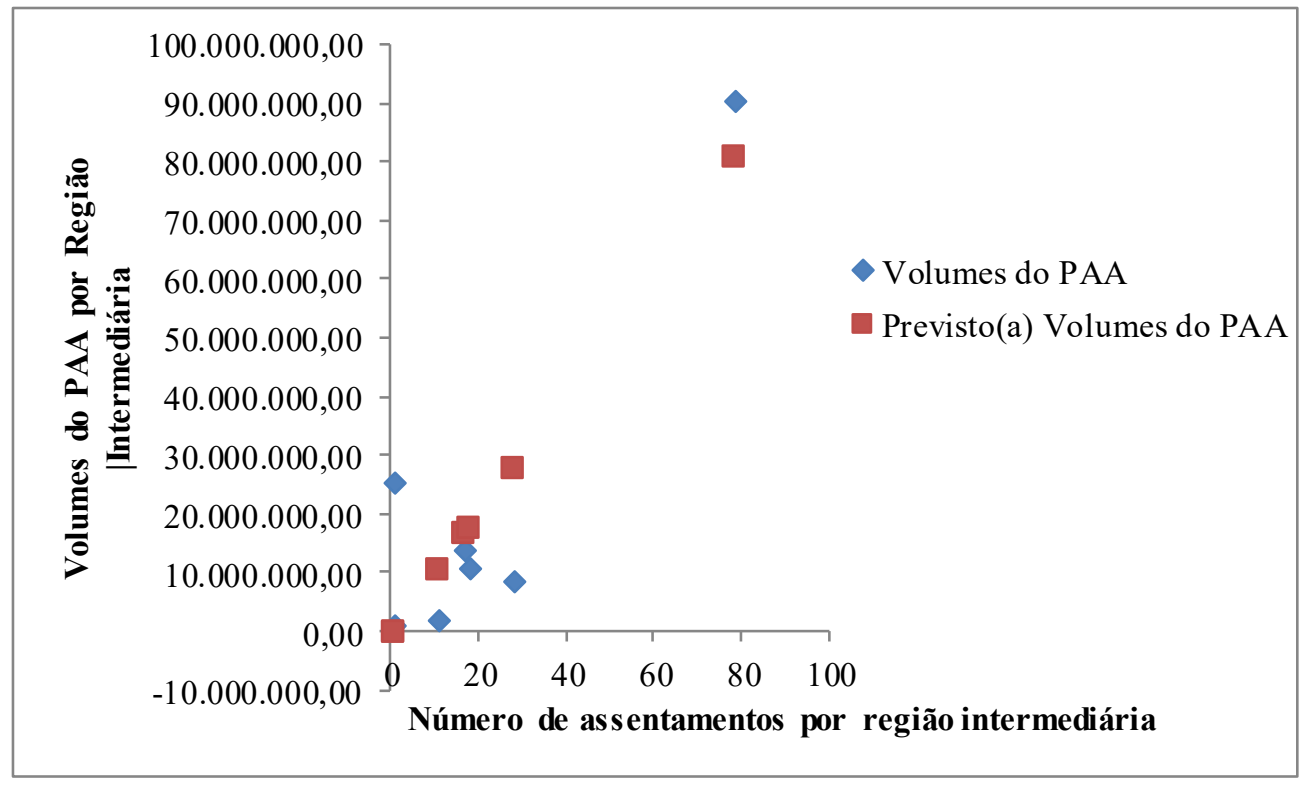

Fonte: elaborado pelo autor. 
O que se pode deduzir a partir dessa análise estatística é que há uma correlação entre a presença de assentamentos rurais com o funcionamento da Política Pública de Aquisição de Alimentos. Isso significa que a quantidade de assentamentos rurais ajuda a explicar, em parte, o maior número de contratos do PAA e o volume dos mesmos. Nisso, pode-se perceber que não somente a região de Chapecó, caracterizada pela territorialização histórica da agricultura familiar e que por isso consegue ser mais aderente ao PAA, mas que uma região como Lages, que não possui essas características tão marcantes em termos de história econômica, ocupou a segunda posição. A presença expressiva de assentamentos rurais de reforma agrária nessa região pode ser uma das razões pelas quais a territorialização do PAA conseguiu obter boa aderência nesta região.

Os assentamentos rurais são uma forma de territorialização da agricultura familiar (CHELOTTI, 2013), ou seja, de reestruturação fundiária com o intuito de fomentar o desenvolvimento dessa forma social de produção. Não somente o PAA, mas outros programas como o PRONAF também foram concebidos como ferramentas para a afirmação dessa territorialização. O que se pode perceber no caso do PAA é que sua funcionalidade enquanto política pública é mais significativa quando existem elementos territoriais convergentes.

Outra hipótese analisada foi mensurar a existência de uma possível correlação estatística entre os valores empenhados pelo PAA nos municípios e os índices de alteração dos estabelecimentos rurais da agricultura familiar. A ideia era visualizar se havia alguma correlação entre os recursos do programa com o aumento/diminuição do número de estabelecimentos rurais desse segmento. Esse aspecto é relevante na medida em que um dos objetivos do PAA enquanto política para o fortalecimento da agricultura familiar é incentivar a reprodução dessa forma social de produção. 
Tabela 1: Índice de alteração dos estabelecimentos rurais e os valores do PAA nos municípios-sede das regiões imediatas do Estado de Santa Catarina

\begin{tabular}{|c|c|c|c|c|}
\hline Município & $\begin{array}{c}\text { Estabelecimentos } \\
\text { da Agricultura } \\
\text { Familiar } 2006\end{array}$ & $\begin{array}{c}\text { Estabelecimentos } \\
\text { da Agricultura } \\
\text { Familiar } 2017 \\
\end{array}$ & $\begin{array}{c}\text { Índice de alteração } \\
\text { dos } \\
\text { estabelecimentos }\end{array}$ & $\begin{array}{c}\text { Valores do PAA } \\
\text { em R\$ 2009-2018 }\end{array}$ \\
\hline Araranguá & 954 & 929 & $-0,0262$ & $366.768,80$ \\
\hline Blumenau & 1062 & 412 & $-0,6211$ & $579.304,48$ \\
\hline Caçador & 1073 & 977 & $-0,0894$ & $856.207,62$ \\
\hline Chapecó & 1616 & 1302 & $-0,1943$ & $3.791 .858,56$ \\
\hline Concórdia & 2723 & 2323 & $-0,1468$ & $2.136 .308,01$ \\
\hline Criciúma & 591 & 388 & $-0,3434$ & $1.383 .042,36$ \\
\hline Curitibanos & 778 & 590 & 0,2416 & $685.254,62$ \\
\hline Florianópolis & 62 & 35 & $-0,4354$ & $769.489,5$ \\
\hline Joaçaba & 461 & 698 & 0,514 & $1.321 .368,84$ \\
\hline Joinville & 1680 & 969 & $-0,4232$ & $1.156 .730,30$ \\
\hline Lages & 469 & 579 & 0,2345 & $6.044 .022,23$ \\
\hline Mafra & 1364 & 1603 & 0,1752 & $1.956 .900,00$ \\
\hline Maravilha & 894 & 724 & $-0,1901$ & $660.466,94$ \\
\hline Pres. Getúlio & 836 & 725 & $-0,1327$ & $189.000,00$ \\
\hline Rio do Sul & 620 & 487 & $-0,2145$ & $161.224,00$ \\
\hline São L. d. Oeste & 1321 & 1047 & $-0,2074$ & $857.132,90$ \\
\hline São M. d. Oeste & 985 & 706 & $-0,1817$ & $37.684 .982,03$ \\
\hline Videira & 767 & 856 & 0,116 & $223.998,71$ \\
\hline Xanxerê & 570 & 567 & $-0,0052$ & $431.600,00$ \\
\hline
\end{tabular}

Fonte: elaborado pelo autor.

Para tal análise foi usado o critério dos municípios-sedes das regiões geográficas imediatas que compõem as 07 regiões intermediárias do Estado de Santa Catarina e que tiveram algum tipo de contrato efetivado no PAA durante os anos de 2009-2018. A correlação foi elaborada com base no cálculo do índice de alteração dos estabelecimentos rurais da agricultura familiar (índice negativo indica a redução de estabelecimentos e índice positivo o aumento) de forma comparada entre os Censos de 2006 e 2017, com o volume de recursos do PAA sob a forma de pagamento aos produtores integrantes de cooperativas/associações participantes do programa. A análise estatística apontou uma correlação fraca entre as variáveis e, portanto, baixíssima aderência explicativa. Desse modo, pelos dados elencados, não se pode inferir que o PAA, por si, tenha conseguido gerar impacto direto na manutenção dos estabelecimentos da agricultura familiar. 
Embora essa correlação possa representar parcialmente um dos reflexos de uma política pública em termos de desenvolvimento rural, é preciso entender o caráter relativo dessa medida analítica, pois se reconhece a necessidade de se testar outras variáveis para ter-se uma compreensão mais ampla e precisa desse tipo de desdobramento. Ademais, se considerado o volume de recursos mobilizado pelo PAA no âmbito territorial, seu impacto na formação da demanda agregada e a geração de renda para as unidades socioprodutivas familiares, pode-se inferir que, se não foi suficiente para reter a redução dos estabelecimentos familiares, certamente contribuiu para que tal redução não tivesse sido ainda maior.

\section{CONSIDERAÇÕES FINAIS}

O Programa de Aquisição de Alimentos-PAA foi instituído como uma política pública para melhorar as condições da soberania e segurança alimentar, bem como para consolidar o Programa de Fortalecimento da Agricultura Familiar (PRONAF). Ao analisar especificamente esse segundo objetivo do programa, pode-se perceber sua importância na distribuição da renda no âmbito regional e na agricultura familiar, além de melhorar a oferta e o acesso à alimentação nos territórios que fazem parte do programa.

A partir dos dados levantados e das análises estatísticas realizadas, pode-se observar que a distribuição regional do PAA em Santa Catarina é influenciada pela territorialização da agricultura familiar. Esta acontece em função da configuração histórica e econômica regional, da maior efetividade da cultura organizativa em termos de associações/cooperativas, da presença de outras políticas públicas anteriores que estimularam tais arranjos, como os assentamentos rurais de reforma agrária e o próprio PRONAF. Nas regiões em que esses aspectos se articulam, os volumes de contratos do PAA foram significativamente mais representativos no período estudado. Por sua vez, o próprio PAA, em seu arcabouço normativo, enseja a retroalimentação desses arranjos gerando uma convergência positiva no que se refere ao fortalecimento da agricultura familiar.

A partir de 2014 o PAA sofreu um processo de retração brusca em termos de volume de recursos e contratos. Apesar disso, um dos efeitos positivos do PAA foi estimular a reinvenção de processos associativos/cooperativos que são, reconhecidamente, ferramentas fundamentais para a reprodução social e para o desenvolvimento da agricultura 
familiar. Ademais, é importante destacar que uma política pública consegue atingir seus objetivos mais amplos quando ocorrem sinergias positivas entre suas prerrogativas normativas e as práticas socioeconômicas e culturais presentes nos territórios.

\section{REFERÊNCIAS}

ABRANTES, José. Associativismo e cooperativismo: como a união de pequenos empreendedores pode gerar emprego e renda no Brasil. Rio de Janeiro: Interciência, 2004.

AFONSO, Juliana Franco. Introdução à econometria. Maringá-PR: UNICESUMAR, 2019.

BECKER, Cláudio; SACCO DOS ANJOS, Flávio. São os mercados institucionais da agricultura familiar um instrumento para o desenvolvimento rural? estudo de caso em municípios do sul do Brasil. Rev. Fac. Agron. La Plata, Vol. 114, nº1, p. 143-152, 2015.

BELIK, Walter. Perspectivas para segurança alimentar e nutricional no Brasil. Saúde e Sociedade v.12, n.1, p.12-20, jan-jun 2003.

BOSETTI, Cleber José. Martelos nas cercas: ainda temos uma questão agrária? Revista NERA, ano 20, vol40, p.11-38, set/dez, 2017.

BOSETTI, Cleber José. Sementes de uma ruralidade camponesa: a experiência do Movimento dos Pequenos Agricultores - MPA no Extremo Oeste Catarinense. Revista IDeAS, v. 11, n. 1-2, p. 102-130, 2017 [publicado em agosto de 2019]

BOURDIEU, Pierre. O poder simbólico. Rio de Janeiro: Bertrand do Brasil, 2005.

BRASIL. Lei n⿳0 10.696, de 02 de julho de 2003.

BRASIL. Decreto no 7.775, de 04 de julho de 2012. Brasília, DF: Presidência da República.

BRASIL. Lei $\mathbf{n}^{0} \mathbf{1 0 . 6 9 6}$, de 02 de julho de 2003. Dispõe sobre a repactuação e o alongamento de dívidas oriundas de operações de crédito rural, e dá outras providências. Brasília, DF: Presidência da República.

CHAYANOV, Alexander. A teoria das cooperativas camponesas. Porto Alegre: UFRGS, 2017.

CHELOTTI, Marcelo Cervo. A dinâmica territorialização-desterritorializaçãoreterritorialização em áreas de reforma agrária na Campanha Gaúcha. Campo Território: revista de geografia agrária, v. 8, n. 15, p. 1-25, fev., 2013. 
CHRISTOFFOLI, Pedro Ivan. Elementos introdutórios para uma história do associativismo e cooperativismo rural no Sul do Brasil. Conference paper, p.169-187, january 2015.

DARLOT, Moacir; LAMINE, Claire; BRANDEMBURG, Alfio. A diversidade dos circuitos curtos de alimentos ecológicos: ensinamentos do caso brasileiro e francês. Agriculturas, v. 10 - n. 2, p 08-13, junho de 2013.

DIAS, Ricardo Cunha; SEIXAS, Paulo Castro. Territorialização de Políticas Públicas, Processo ou Abordagem? Revista Portuguesa de Estudos Regionais, $n^{\circ}$ 55, Vol 1, p. 47 60, 2019.

FLIGSTEIN, Neil; DAUTER, Luke. A sociologia dos mercados. CADERNO CRH, Salvador, v. 25, 66, p. 481-504, Set./Dez. 2012.

GIL, Antônio Carlos. Métodos e técnicas de pesquisa social. São Paulo: Atlas, 2008.

GOTTMANN, Jean. A evolução do conceito de território. Boletim Campineiro de Geografia, v. 2, n. 3, p. 29-47, 2012.

GOULARTI FILHO, Alcides. Formação econômica de Santa Catarina. Florianópolis: UFSC, 2007.

GRISA, Cátia; SCHIMITT, Cláudia Job; MATTEI, Lauro; MALUF, Renato; LEITE, Sérgio Pereira. O programa de aquisição de alimentos (paa) em perspectiva: apontamentos e questões para o debate. Retratos de assentamentos, vol. 13, nº1, p. 137-170, 2010.

GRISA, Cátia.; SCHNEIDER, Sérgio. Três Gerações de Políticas Públicas para a Agricultura Familiar e Formas de Interação entre Sociedade e Estado no Brasil. RESR, Piracicaba-SP, Vol. 52, n 1, p.125-146, 2014.

HESPANHOL, Rosângela Aparecida de Medeiros. Programa de Aquisição de Alimentos: Limites e potencialidades de políticas de segurança alimentar para a agricultura familiar. Soc. \& Nat., Uberlândia, Vol. 25, n³, p. 469-483, set/dez/2013.

INSTITUTO BRASILEIRO DE COLONIZAÇÃO E REFORMA AGRÁRIA (INCRA). Assentamentos rurais. Brasília: INCRA, 2019.

LEITE, Sérgio Pereira. Ruralidades, enfoque territorial e políticas públicas diferenciadas para o desenvolvimento rural brasileiro: uma agenda perdida? Estudos Sociedade e Agricultura, Vol. 28, №1, p. 227-254, fev. a mai. 2020.

MALUF, Renato. O Novo contexto internacional do abastecimento e da segurança alimentar In: Belik, W \& Maluf, R. Abastecimento e Segurança Alimentar. Campinas: Unicamp, 2000.

MINISTÉRIO DA AGRICULTURA, PECUÁRIA E ABASTECIMENTO (MAPA). Dados do PAA, Brasília, 2019. 
MCMICHAEL, Philip. Regimes alimentares e questões agrárias. Porto Alegre: UFRGS, 2016.

OLIVEIRA, Ivnna Gurniski; CHATALOV, Renata Cristina de Souza. Estatística econômica. Maringa-PR: Unicesumar, 2017.

PRZYBYZESKI, Silvana. Aquisição institucional de produtos da agricultura familiar: apontamentos sobre aspectos operacionais da política pública. Revista Grifos, nº 49, vol 1, p. 49-66, 2020.

RAFESTIN, Claude. A produção das estruturas territoriais. In: SAQUET, Marco Aurélio; SPOSITO, Eliseu Silvério (orgs) Territórios e territorialidades: teorias, processos e conflitos. São Paulo; UNESP, 2009.

INSTITUTO BRASILEIRO DE GEOGAFIA E ESTATÍSTICA (IBGE). Regiões geográficas. Rio de Janeiro: IBGE, 2017.

ROVER, Oscar; RIEPE, Ademir de Jesus. A relação entre comercialização de alimentos e princípios agroecológicos na rede de cooperativas de reforma agrária do Paraná/Brasil. Desenvolv. Meio Ambiente, v. 38, p. 663-682, agosto 2015.

SABORIN, Eric. Camponeses do Brasil: entre a troca mercantil e a reciprocidade. Rio de Janeiro: Garamond, 2009.

SAQUET, Marco Aurélio; BRISKIEVICZ, Michele. Territorialidade e identidade: um patrimônio no desenvolvimento territorial. Caderno Prudentino de Geografia, $n^{0} \mathbf{3} 1$, vol.1, p. 03-16, 2009.

SCHNEIDER, Sérgio; SCHUBER, Maycon Noremberg; ESCHER, Fabiano. Regimes agroalimentares e o lugar da agricultura familiar: uma apresentação ao debate. Revista Mundi Meio Ambiente e Agrárias. Curitiba, PR, vol.1, no 1, p. 1-20, jan./jun, 2016.

TECCHIO, Andreia; CAZELLA, Ademir Antônio. Territorialização da ação pública no meio oeste contestado: uma ferramenta para o enfrentamento da pobreza? Revista Grifos Unochapecó, Vol. 30, Núm. 53, 2021.

TRICHES, Rozane Márcia; SCHNEIDER, Sérgio. Alimentação escolar e agricultura familiar: reconectando o consumo à produção. Saúde soc., São Paulo, v. 19, n. 4, p. 933945, Dec. 2010.

TRICHES, Rozane Márcia, GRISA, Cátia. Entre mudanças e conservadorismos: uma análise dos programas de aquisição de alimentos (PAA e PNAE) a partir da retórica da intransigência. Revista Nera - ano 18, nº 26 - edição especial, p. 10-27, 2015. 